AperTO - Archivio Istituzionale Open Access dell'Università di Torino

\title{
Schooladvise: Designing a Reputation System for Educational Services through Service Design and Business Modeling
}

\section{This is the author's manuscript}

Original Citation:

\section{Availability:}

This version is available http://hdl.handle.net/2318/1577126

since 2021-09-26T22:22:36Z

Publisher:

Institute of Electrical and Electronics Engineers Inc.

Published version:

DOI:10.1109/ICEBE.2015.52

Terms of use:

Open Access

Anyone can freely access the full text of works made available as "Open Access". Works made available under a Creative Commons license can be used according to the terms and conditions of said license. Use of all other works requires consent of the right holder (author or publisher) if not exempted from copyright protection by the applicable law. 
This is the author's final version of the contribution published as:

Capecchi, Sara; Giraudo, Mauro; Negro, Claudia; Pisano, Paola. Schooladvise: Designing a Reputation System for Educational Services through Service Design and Business Modeling, in: Proceedings - 12th IEEE International Conference on E-Business Engineering, ICEBE 2015, Institute of Electrical and Electronics Engineers Inc., 2015, 9781467380027, pp: 263-268.

The publisher's version is available at:

http://ieeexplore.ieee.org/lpdocs/epic03/wrapper.htm?arnumber=7349978

When citing, please refer to the published version.

Link to this full text:

http://hdl.handle.net/2318/1577126 


\section{Schooladvise: designing a reputation system for educational services through service design and business modelling}

\author{
Sara Capecchi \\ Dipartimento di Informatica, \\ Università di Torino, Italy \\ capecchi@di.unito.it
}

\author{
Mauro Giraudo \\ Dipartimento di Informatica, \\ Università di Torino, Italy \\ giraudo@di.unito.it
}

\author{
Claudia Negro \\ ICxT Research Centre, \\ Torino, Italy \\ negro.claudia@gmail.com
}

\author{
Paola Pisano \\ ICxT Research Centre, \\ Torino, Italy \\ pisano@di.unito.it
}

\begin{abstract}
In this paper we analyse the use of an extension of tools for service design and business conceptual modelling toward reputation system design for the realisation of Schooladvise a platform for educational services reputation management. The work described in the present paper originates from the intuition that business process modelling, service design and reputation system modelling share many needs, aims and problems: to represent a variety of entities involved in the related domains, to improve services/business in order to meet the users need; moreover they all involve stakeholders with very different background and skills, a problem known as socio-technical mismatch. The objective and the contribution of the analysis presented in this paper is to gather feedback on the proposed modelling language from the end-users (requirements engineers and domain experts) while applying it to a complex case study.
\end{abstract}

\section{INTRODUCTION}

Reputation can be defined as the expectation about an entity's behaviour based on informations about or observations of its past behaviour and it is used to make a value judgement about another entity (object or person). In spite of the latest governments' efforts to use new technologies in order to improve citizen participation and information exchange between citizens and government, reputation system evaluating public services are almost absent. The few reputation systems implemented so far are very simple and lack in showing relevant features of the service: 1) the final representation often fails to distinguish different attributes/characteristics concerning the entity holding the reputation. The resulting value is an overall one that does not reflect the related contexts in which it is earned; then the informations gathered through feedback collection are not very useful even for service provider since it is hard to structure, interpret and relate them to the associated part of service/product; 2) the information used to built reputation is completely subjective, that is entirely rely on users' feedbacks, even concerning attributes that could be objectively measured.

There are lots of sources holding objective informations that could and should be used to compose an entity's reputation together with users feedbacks i.e. quality controls/standards and open data. Quality control and guarantee organizations exist for a wide range of products and services. A standard/quality certification is a document that provides requirements and specifications that can be used consistently to ensure that products and services are fit for their purpose [1]. Nowadays quality certifications provided by standardization organizations do not improve reputation perception of a service among service users, simply because it is not clear to users what are the measurable benefits brought by it. Open data provided by administrations in the latest trend of Open Government can contain relevant informations concerning services such as schools, hospitals. This information has a significant potential for use in reputation systems as part of the reputation of a given service. At the moment the potential use of open data in this direction is far from being realized.

One of the main causes of the deficiencies above described is that software engineering methodologies do not provide the right level of support for reputation systems, starting from the very early stages, that is, by the use of a dedicated conceptual model and the related modelling language. So far reputation models have been added after-the-fac in an ad-hoc perspective, limiting re-usability and suffering scalability problems. In [2] we analysed the extension of tools for service design and business conceptual modelling toward reputation system design following the intuition that business process modelling, service design and reputation system modelling share many needs, aims and problems: to represent a variety of entities involved in the related domains, to improve services/business in order to meet the users need; moreover they all involve stakeholders with very different background and skills, a problem known as socio-technical mismatch.

A reliable reputation system, where feedbacks are well structured and give hints about parts of the business/service that are responsible for bad/good perception by user, would greatly help in meeting the user's need.

We proposed an extension of some of the tools for business innovation and service modelling towards the representation of concepts and requirements for reputation systems. In particular we extended part of Value Delivery Modelling Language (VDML) and Service Modelling Language (ServiceML) [3]. VDML abstracts the organization structure of an enterprise, the creation and exchange of value, the capabilities that produce that value, the management of resources people and roles, interactions with business partners. VDML is under development as an OMG (Object Management Group [4]) standard.

ServiceML Touch-point model allow to describe the customer experience while using a service. These languages provide the right abstractions to represent the concepts related to reputation systems in the design phase when roles and entities must be clearly detected: reputation sources and target roles (service 
user, service provider, certification service third party), parts of the service that can be objectively and subjectively evaluated etc. The aim is to provide a model to allow mutual understanding between reputation system committee and designers.

In this paper we describe how we exploited the model proposed [2] for the requirements' collection and the design of Schooladvise a platform for kids educational services evaluation and reputation. The aim of the analysis presented in this paper is to gather feedback on the proposed model from the endusers (requirements engineers and domain experts) through the use of a practical case. The motivation for this analysis is the following: we are currently developing a visual editor to use the proposed modelling language (by extending VDML and ServiceML meta-models on Eclipse Modelling Framework [11]); following [5] we used a formative evaluation to identify problems in the design tool during its development process. We then followed a user-centred design approach focusing on the adequacy of the modelling features for expressing reputation systems concepts as well as the usability of the modelling language through the application on a practical case. The design of Schooladvise has been a challenge from many points of view since the socio technical gap between stakeholders is quite big: a nursery service provides several tangible and intangible value propositions that should be evaluated and considered. On the other hand it is quite hard for the designer of a reputation system to dig into details of such a peculiar context.

The rest of the paper is organised as follows: Section II introduces Schooladvise idea and the design challenges for its development; Section III illustrates the design of Schooladvise through the use of the modelling language proposed in [2]; Section IV presents the evaluation results of the modelling language by users while designing Schooladvise; Section V provides some detail about Schooladvise implementation; Section VI provides a comparison with Schooladvise competitors, finally Section VII concludes the paper.

\section{SCHOOLADVISE DESIGN CHALLENGES: A REPUTATION SYSTEM FOR EDUCATIONAL SERVICES}

Following [6] we introduce the terminology used to refer to basic objects involved in a reputation system. Reputation is composed of reputation statements with the following structure: a source makes a claim about a target. A source is any entity that can make a reputation claim (users, third party certifications etc.). A claim is the value that the source assign to the target. Claims have a type and a value. In the present paper we abstract from different types of claims (quantitative vs qualitative, raw vs normalised), we just distinguish between claims that come from a subjective opinion and those coming from an objective measurement: for instance a claim about delivery service of an e-store could come from subjective comments of customers or from objective data (percentage of delivery delays, percentage of damaged packagings). A target is any reputable entity that can be the object of a reputation claim. To summarise let us consider the following reputation statement: user $\mathrm{x}$ rates 4 stars over 5 product $y$; user $\mathrm{x}$ is the source, 5 star is the claim type, 4 star is the claim value, product $\mathrm{y}$ is the target.

As outlined in [7], [8], [9] existing reputation systems show many deficiencies: i) lack of connection between reputation statements and its context, e.g judgement about product, de- livery, price, interaction with seller is melted in a 5 star claim type plus a detailed written feedback; ii) incomplete or noncomprehensive provided information which causes incorrect perception of the service reputation by the user; iii) no distinction between expressions of fact and opinion, that is between objective and subjective claims; iv) lack of a proper identification mechanism that should allow only effective users of a service to evaluate it thus avoiding fake feedbacks. There are lots of reputation websites that do not check ratings attendability (TripAdvisor.com, RealSelf.com, Glassdoor.com, Honestly.com, RateMyProfessors.com). This deficiency deeply influences their credibility and usefulness.

In order to overcome the problems above an adequate modelling language should be able to represent: source and target roles, target entities that can be subjectively and objectively measured, the complete multiplicity of targets that compose an overall service/value, the link between targets of claims and roles in the business service responsible for them: each part of a service that is evaluated should be directly and easily connected with roles and actors responsible for it in the business organisation.

Our use case Schooladvise is a web platform that collects reviews of schools The aim of the platform is to allow parents to orient themselves within the educational offer and choose the appropriate school for their children. Thus, specific objectives in designing Schooladvise are:

- the creation of a platform collecting both subjective feedbacks from users and objective data (collected from open data and certifications)

- to check that the reviews are inserted only by parents of children who really attended reviewed school

- concerning the subjective reviews, users should be able to evaluate nurseries on the basis of specific aspects, easily intelligible and comparable (e.g. canteen, teachers competencies, safety, extra-curricular activities)

- the multiplicity of factors that constitute the reputation of nurseries makes the requirement analysis quite complex for programmers so there is a need for a common language between stakeholders.

\section{DESIGNING SCHOOLADVISE WITH VDML AND SERVICEML}

To address the above requirements we need model describing the activities, competences, resources and skill are strictly linked and connected to create the value delivered by the organization to customers, that is, a business model. To support
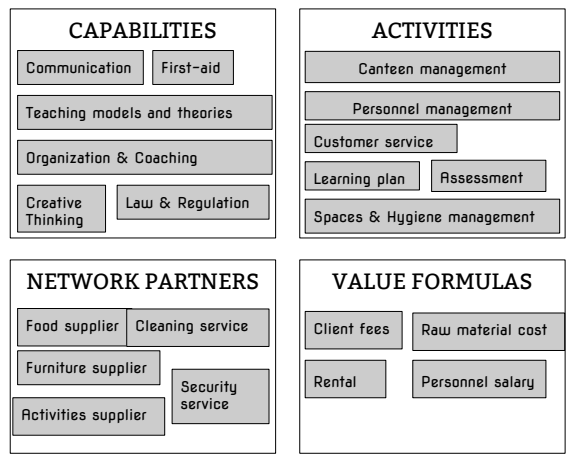

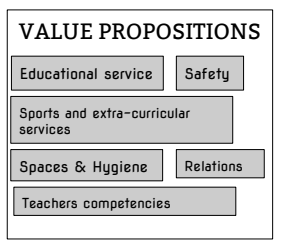

CUSTOMERS

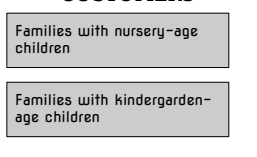

Fig. 1. Nursery cube model 
the creation of highly complex businesses that deal with volatile technologies new procedures for creating and testing business models have emerged. One of these developments is the CUBE model proposed in [10], a conceptual instrument that helps the definition of 1) customers 2) value proposition 3) value formula 4) network partners 5) capabilities 6) activities. Customers represent that segment of buyer interested in the value proposition of the organization; value proposition is the value perceived by target customers of the product and service offering; value formula is a realistic view of the sources of revenue and cost; network partners represent all the voluntarily initiated cooperative agreement between two or more companies in order to create value for the customer; capabilities are the competencies necessary that should be created in house and contribute to the power of a business model; activities are all the operations to put in action value proposition. Figure 1 describes the cube model associated with our case study. The value proposition of the school is centred on the quality of proposed services, spaces, relationship, and competencies. Customers are clustered by the need of clear and structured information about educational services and the use of the internet as a source of information. The capabilities are centred on all those activities that help to maintain the quality of service and the users experience. The network is based on supplier partnership which represents the cost of the value formula. Value Delivery Modelling Language supports the six views of the cube with dedicated diagrams.

Value exchange proposition diagram depicts roles and exchanged products and services expressed as value propositions. The value proposition exchange diagram related to Schooladvise is illustrated in Figure 2. Value proposition is composed by eight elements divided into two groups: 1) first group: it's the closest to the customer perception and composed by educational service, canteen, spaces, interaction with families; 2) second group: it's the closest to the partners and it's composed by food, activities, cleaning and security devices. These elements depend by out-house partnership expertise. In order to

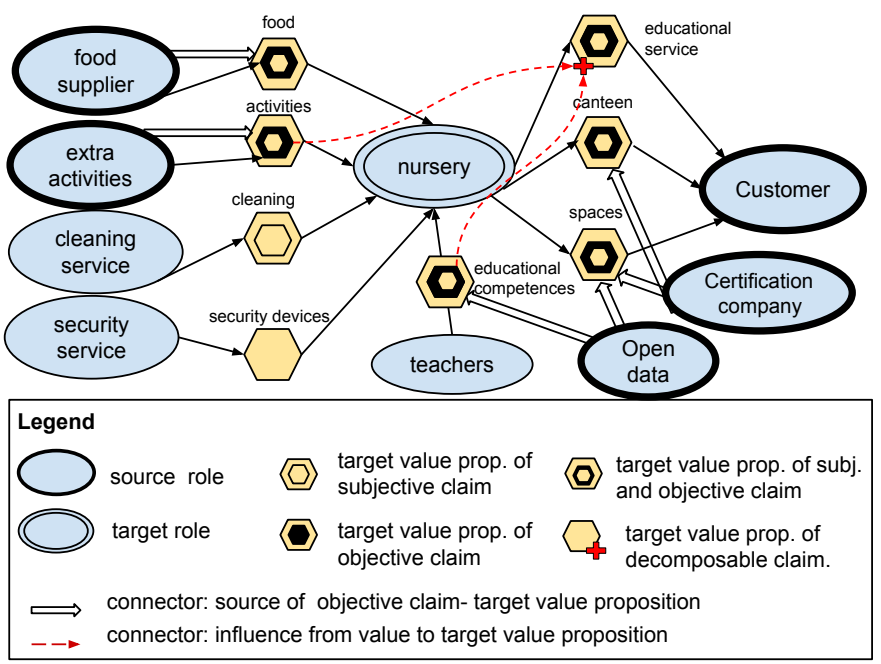

Fig. 2. Value proposition exchange diagram of nursery

represent the abstractions needed to model reputation systems requirements we extended VDML by providing roles and value proposition specialisations and new relations between them. A source role is any participant that can make a claim about a target and is identified with a thick oval. In our example source roles are customer who can express claims about any aspect of the nursery, food supplier who can certificate provenance and quality of the delivered food, supplier of extra activities who provides data about the usefulness of the proposed courses. A target role is any participant that is the object of a reputation system and it is represented with a double oval. In our example the target of the reputation system is the nursery.

Value proposition. Value propositions are the ideal target of reputation claims: source roles provide their judgements, data and measurements about products and services that compose value propositions. Targets of reputation statements can be evaluated with objective data and measurements or with subjective comments/ratings. Then, value propositions can be target of objective, subjective claims or both. We denote them with three different kinds of hexagons depicted in Figure 2: i) food, activities, educational competencies, educational services, canteen and spaces can be evaluated objectively (from providers/certification companies collecting data) and subjectively (from users); ii) cleaning can be evaluated subjectively by users.

White arrows represent a connection between a source role and its objectively measured target; in our example they connect: i) the certification company to spaces and canteen since it certifies spaces safety (room/person, security devices, emergency exits) and food preparation (kitchen/tools adequacy, food conservation); ii) food supplier provides evidences about provenance and ingredients; iii) extra activities providers can demonstrate the skills of their staff by providing documents about their training; iv) open data provided by public administration can show important information about public nurseries concerning requirements for both spaces and teachers training. We are currently working with educational service department of Torino council in order to integrate these data into Schooladvise.

Target value propositions decorated with a red cross can be further decomposed in other targets with associated claims. In our example a claim about the educational service can be further decomposed in two parts: one about the teacher competences and one about the quality of extra activities; these two parts correspond to value propositions provided by partners teachers and extra activities supplier. The above dependency between value propositions is represented with a red dashed arrow. For simplicity we do not represent the relation between source and target of a subjective claim. The reason is that the source of subjective claims is usually a customer/user whose experience in using the service is analysed in the following throughout the use of ServiceML service journey maps: we rely on ServiceML Service Journey Maps which describe the typical flow of activities, encapsulated as a touch-point, which a participant, service provider and other stakeholders perform in a service execution.

Figures 3, 4 illustrates the general and daily experience of families in nurseries. An actor can either initiate a touch-point (represented by open arrows) or be involved, through some inputs or outputs, in a touch-point execution (represented by dotted lines). Closed arrows link one touch-point to the next following execution sequence. Figure 3 illustrates how a child and his family live on a daily basis the experience inside the nursery of our example. A service user nursery begins his experience at the school entrance, evaluating ergonomics and safety aspects of space. The second touch-point is welcome 


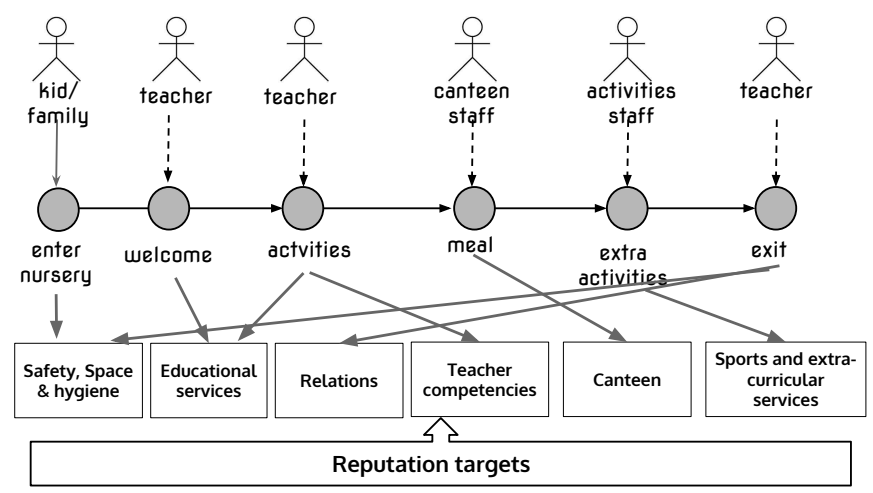

Fig. 3. Daily routine service journey map

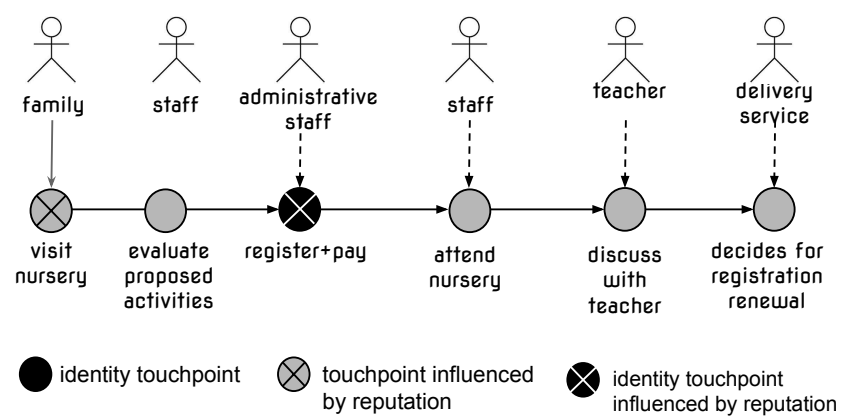

Fig. 4. Nursery service journey map

time, that involves teacher, as educational activities, meal involves the staff canteen, and extra-curricular activities may involve external personnel specialized in individual activities. A service journey map helps to understand how services are being experienced by customers. Therefore, ServiceML Touch-points offer a great model to involve stakeholders in designing service feedback. We add two kinds of touchpoints: verification touch-points are used to represent points of interaction where reputation claim validity can be checked, for instance by assigning a precise identity to the user and/or by detecting a proof that she really used the service; touchpoints influenced by reputation are those touch-points where the user behaviour can be influenced by reputation of the service. For instance in Figure 4 we identify the enrolment to school as the touch-point where a user can be uniquely identified and as the confirmation that the user has effectively used the service: this will help in designing solutions to avoid fake feedbacks. The behaviour of a customer in visit nursery and register and pay touch-points is influenced by reputation of the school: a customer is more encouraged to visit a nursery and register his children if its reputation is good. The different touch-points a customer encounters during its journey can also be related to corresponding targets of reputation claims. In order to evaluate the nursery the customer could express claims about different aspects: spaces, activities (curricular and extracurricular), price.

The analysis performed so far can be summarised in Figures 5,6 where all the reputation source-target pairs are associated with 1) an attribute indicating if they are related to objective or subjective claim, 2) the corresponding value proposition and
3) the role responsible for creating it.

Both the subjective evaluations expressed by customers and

\begin{tabular}{|c|c|c|c|c|}
\hline $\begin{array}{c}\text { Reputation } \\
\text { Source }\end{array}$ & $\begin{array}{c}\text { Reputation } \\
\text { Target }\end{array}$ & $\begin{array}{c}\text { Subj/ } \\
\text { Obj }\end{array}$ & $\begin{array}{c}\text { Associated value } \\
\text { proposition }\end{array}$ & Responsible role \\
\hline Family & spaces cleaness & $\mathrm{S}$ & spaces & cleaning service \\
\hline Family & spaces confort & $\mathrm{S}$ & spaces & owner \\
\hline Family & spaces safety & $\mathrm{S}$ & spaces & owner/security service \\
\hline Family & interactions with staff/teachers & $\mathrm{S}$ & interaction with family & staff, teachers \\
\hline Family & educational services quality & $\mathrm{S}$ & educational services & teachers/ activities supplier \\
\hline Family & teacher skills/activities & $\mathrm{S}$ & teacher competences & teachers \\
\hline Family & Canteen service quality & $\mathrm{S}$ & Canteen service & staff/food supplier \\
\hline
\end{tabular}

Fig. 5. Summary of source-subjective targets pairs associated with the corresponding value proposition and the role responsible for creating it.

\begin{tabular}{|c|c|c|c|c|}
\hline $\begin{array}{c}\text { Reputation } \\
\text { Source }\end{array}$ & $\begin{array}{c}\text { Reputation } \\
\text { Target }\end{array}$ & $\begin{array}{c}\text { Subj/ } \\
\text { Obj }\end{array}$ & $\begin{array}{c}\text { Associated value } \\
\text { proposition }\end{array}$ & Responsible role \\
\hline Food supplier & food provenience & 0 & food & Food supplier \\
\hline $\begin{array}{c}\text { Extra activities } \\
\text { supplier }\end{array}$ & staff training & 0 & extra activities & Extra activities supplier \\
\hline Open Data & spaces, room/person & 0 & spaces & owner/security service \\
\hline Open Data & teachers training & 0 & educational skills & teachers \\
\hline Certification company & spaces safety & 0 & spaces & owner/security service \\
\hline Certification company & canteen quality & 0 & canteen service & staff \\
\hline
\end{tabular}

Fig. 6. Summary of source-objective targets pairs associated with the corresponding value proposition and the role responsible for creating it.

objective data can be measured and stored with associated values in order to analyse and compare services' performance, improvements and bottlenecks. In VDML a value is a measurable benefit delivered to a recipient in association with a deliverable that would influence the desirability of a service. VDML supports value measurement and the computations to assess the impact of performance of specific capabilities on the cost, quality of end services. Indeed, VDML incorporates the SMM (Structured Metrics Metamodel) specification to represent the measurement libraries and the measurable properties of model element: in SMM, a measure is a method that is applied to characterize an attribute of something by assigning a comparable quantification or qualification.

While modelling activities, the analyst can build a VDML measurement dependency graph like that in Figure 7. The plus (+) and minus (-) signs on the arcs indicate if the source measurement increases or decreases the target measurement. The graph depicts the aggregations of value measurements that model satisfaction levels of the value proposition.

The analysis performed so far on business networks, collaborations and value creation helps in detecting a structure for identification of sources of value contributions that built business/service reputation.

\section{Modelling language evaluation}

Following [5] we evaluated our modeling language for reputation system development focusing on the following points: modelling language a usability, detection of missing concepts, usability of graphical representation, concepts' semantics clarity.

The usability criteria used in or evaluation are: effectiveness 


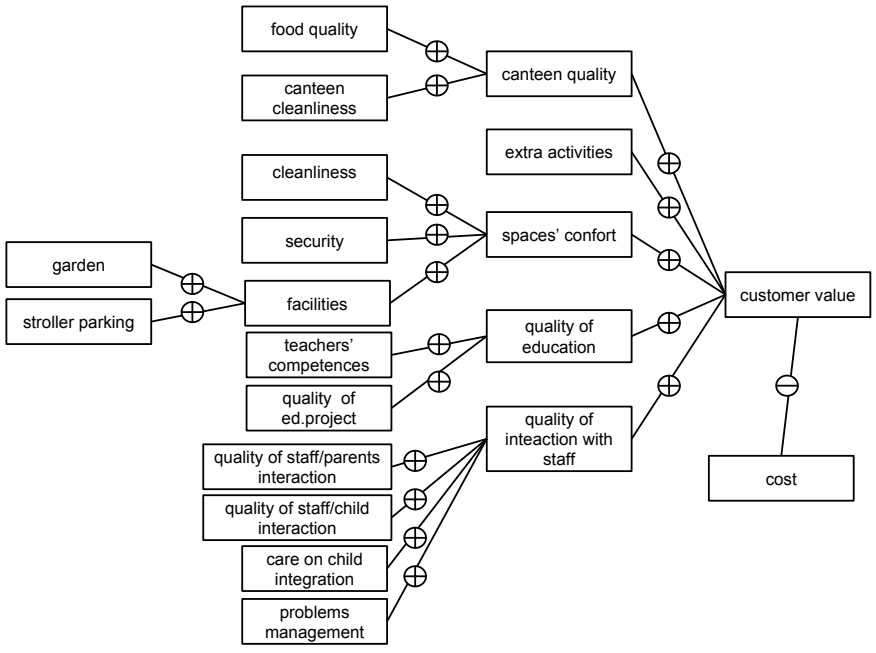

Fig. 7. Measure graph of the online store values

which measures how users are able to achieve their specified goals through design, efficiency which focuses on the effort made by users to learn and use the modelling language, finally satisfaction checks the overall impression collection feedbacks by users.

Since the very early stages of Schooladvise creation, we involved end-users of the modelling language in evaluation activities. Users are all stakeholders who interacted with the modelling language and tool: two programmers, two software analysts, around 20 stakeholders from nurseries' staff/owners/managers. Following [5] users' experience was gathered by the use of forms and by observing their interaction during the use of the model.

Forms. Two forms were given to users: one focusing on the knowledge of the modeling language and one on the concepts and graphical representations of the modeling concepts. The aim of the first form was to detect the degree of knowledge participants had about the modeling language and tool before using it and to discover potential initial difficulties in understanding main concepts. The second form was used during requirement collections and design phases. The form provided a list of all concepts of the modeling language with its corresponding graphical representation. For each concept participants should answer whether the concept is well-defined, useful and whether the graphical representation is adequate. If any criterion was not full-filled, participants should write down the problem in natural language.

Observation. The method of observation was carried to identify user's problems during the modeling process from an external point of view (the observer). The observer keeped track on the discussions between the stakeholders.

In the following we summarize the results gathered in the users' answers and from external observation:

- Participants noted that the modelling language is quite complex for people who are not experts in business models. This issue confirms the difficulties due to the socio-technical mismatch. Programmers and software analyst needed to correctly model all the aspects related to the delivery of value proposition and network business collaboration of educational services. For this purpose a good training for the modelling language was an essential prerequisite.
- A missing feature is the direct representation of claims' type and a value (e.g. 5 stars, 5 likes). This feature will be included in the tool by extending the tables summarizing reputation sources and targets.

- Staff from nursery asked for a clearer comparison between objective and subjective claims related to the same target value proposition

- The modelling effort to provide nurseries with insight regarding the connection between user satisfaction and the enterprise organisations and responsibilities was highly appreciated by nurseries managers and owners since this analysis is expected to both improve outcomes and reduce the cost of services.

The evaluation of the modeling language has greatly helped us in identifying problems to be considered in the current development of the tool. We found that few concepts are missing but there are several usability issues concerning the representation of concepts specific to business modelling and value delivery.

\section{IMPLEMENTATION}

For the implementation of Schooladvise.com we used Ruby on Rails, an open source framework for web applications [11]. Ruby on Rails architecture is strongly inspired by the paradigm Model-View-Controller (MVC) and has as its goals simplicity and the possibility of developing applications of practical interest with less code than other frameworks.

In our implementation we created the following Classes as primary entities: School represent informations necessary for the visualization of the Schools, User contains data of platform's end-users, Review contains user s'evaluations. To describe services of the Schools the following Classes were also created: Skillcard, Internalstructure and Environment, Trainingoffer, Growthpath and Activities, Staffs, Entrancetime and Exittime co. All of these elements are subject to evaluation by users. The platform's homepage is simple and presents to users with a free search field or with options. If a user is already registered on the platform can then enter a review for the school, one for year, to prevent multiple reviews by the same user. The school can protect themselves from false reviews associating itself a list of fiscal code of children who attend it. The choice of Ruby on Rails has facilitated the management of the various views and data that are placed, are these schools or user reviews, because management of classes and of their attributes to be displayed, either in insertion or in storage, is completely transparent to the programmer, if not for the aspects of graphic design. Figure 8 shows a screenshot of detailed ratings as displayed to users.

\section{RELATED WORKS AND COMPETITOR ANALYSIS}

Related works. There are few works that consider reputation requirements at the early stages of system design. Reputation Object Model [7] is a conceptual model identifying many concepts related to reputation systems. [12] propose and extension of UML for specifying trust and reputation requirements. Some of these concepts can be easily mapped to ours, while others related to reputation claims measurements, computing functions and collecting algorithms are not present in our proposal. The reason is that, so far, we have addressed the problem of modeling reputation objects and not reputation 


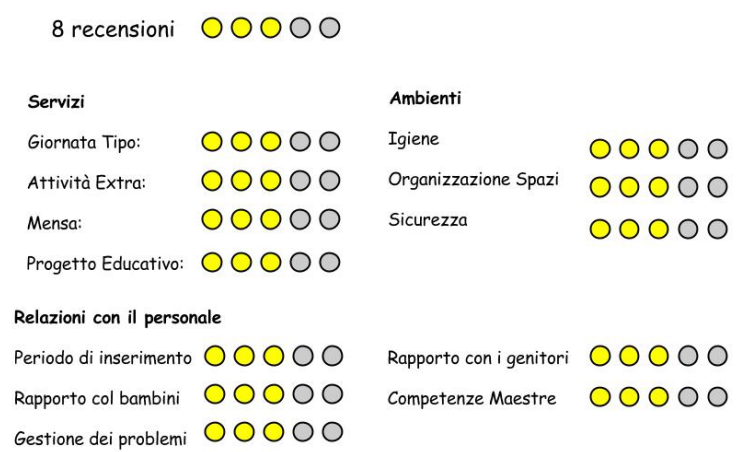

Fig. 8. Detailed rating of nurseries in Schooladvise.com

measurements and algorithms. A future step in this direction is discussed in Section VII. The distinguishing feature of our proposal is that we model reputation-related concepts on a modeling language that has been expressively designed for overcoming the socio-technical mismatch that is usually present between developers and business committees. We refer to [6] and [9] for a description of development methodology that should be followed when designing and developing reputation systems. In [3] service journey's touch-points are decorated with a level of satisfaction that comes from users' feedbacks. We took inspiration from their emotional touchpoints to map different stages of users' journey to fields of users' feedbacks surveys.

\begin{tabular}{|l|l|l|l|}
\hline Competitor \Features & $\begin{array}{l}\text { Objective } \\
\text { data }\end{array}$ & $\begin{array}{l}\text { Structured } \\
\text { subjective } \\
\text { feedback }\end{array}$ & $\begin{array}{l}\text { Check on } \\
\text { reviewers } \\
\text { identity }\end{array}$ \\
\hline $\begin{array}{l}\text { Schooladvisorco.uk } \\
\text { (reviews about primary and secondary } \\
\text { schools in UK) }\end{array}$ & $\mathrm{X}$ & $\mathrm{X}$ & \\
\hline $\begin{array}{l}\text { Mumadvisor.com } \\
\text { (reviews about any aspect of children } \\
\text { and mum's activities in the town of } \\
\text { Milan) }\end{array}$ & & $\mathrm{X}$ & \\
\hline $\begin{array}{l}\text { Eduscopio.it } \\
\text { (ranking of italian high schools and } \\
\text { technical college, based on the votes } \\
\text { obtained at the University by former } \\
\text { students) }\end{array}$ & $\mathrm{X}$ & & \\
\hline
\end{tabular}

TABLE I. SCHOOLAVISE'S COMPETITORS

In Table I we compare Schooladvise with other platform for educational services evaluation.

\section{CONCLUSION}

In this paper we tested a model to support IT designers in the capture of high-level reputation management requirements and their implementation by exploiting tools and models for service design and business modeling.

According to [13] there are 4 decisions to select relevant informations concerning reputation targets:

- what actions are relevant for reputation? the VDML diagrams proposed and extended in this case study allow coarse grained and fine grained detection of the action that are relevant for target's reputation;

- how to obtain information about these actions? the analysis performed on the use case shows how to decide whether collecting informations by asking users' feedback or storing objective data;
- how to aggregate/display information? we showed how to structure reputation according to the variety of different aspects that compose service/business value perception by user; according to [14] data alone does not create transparency. Analysis and visualisation are required to describe the relationship between data, feedbacks and context;

- how deal with manipulation and gaming: points of identification and objective information? the identification points in service journey maps and the objective data included in the reputation are two powerful means to avoid fake feedbacks and informations.

More specifically the benefits for developers could be listed as: consistent terminology, appropriate levels of abstraction facilitating the development of the model in several domains and ensuring the simplicity and reusability of the embedded information, support for identifying the appropriate stakeholders, users and relevant sources of informations.

Moreover, linking customer feedbacks as part of an appropriate reputation systems to specific business model elements can easily improve the organization output in line with the customer need and features.

\section{REFERENCES}

[1] ISO, http://www.iso.org/iso/home/standards.htm.

[2] S. Capecchi and P. Pisano, "Reputation by design: using VDML and ServiceML for reputation systems modeling," in Proc. of the 11 th IEEE International Conference on e-Business Engineering (ICEBE), 2014.

[3] A. J. Berre, Y. Lew, B. Elvesaeter, and H. de Man, "Service Innovation and Service Realisation with VDML and ServiceML," 2012 IEEE 16th International Enterprise Distributed Object Computing Conference Workshops, vol. 0, pp. 104-113, 2013.

[4] “Object Management Group," http://www.omg.org/.

[5] S. Trösterer, E. Beck, F. Dalpiaz, E. Paja, P. Giorgini, and M. Tscheligi, "Formative user-centered evaluation of security modeling: Results from a case study," IJSSE, vol. 3, no. 1, pp. 1-19, 2012. [Online]. Available: http://dx.doi.org/10.4018/jsse.2012010101

[6] R. Farmer and B. Glass, Building Web Reputation Systems, 1st ed. USA: Yahoo! Press, 2010

[7] R. Alnemr, S. Koenig, T. Eymann, and C. Meinel, "Enabling usage control through reputation objects: A discussion on e-commerce and the internet of services environments," J. Theor. Appl. Electron. Commer. Res., vol. 5, no. 2, pp. 59-76, Aug. 2010. [Online]. Available: http://dx.doi.org/10.4067/S0718-18762010000200005

[8] Y. Yao, S. Ruohomaa, and F. Xu, "Addressing common vulnerabilities of reputation systems for electronic commerce," J. Theor. Appl. Electron. Commer. Res., vol. 7, no. 1, pp. 1-20, Apr. 2012. [Online]. Available: http://dx.doi.org/10.4067/S0718-18762012000100002

[9] R. Alnemr and C. Meinel, "Why rating is not enough: A study on online reputation systems," in Collaborative Computing: Networking, Applications and Worksharing (CollaborateCom), 2011 7th International Conference on, Oct 2011, pp. 415-421.

[10] P. Lindgren and O. H. Rasmussen, "The Business Model Cube," Journal of Multi Business Model Innova-tion and technology, 2013, 3rd edition.

[11] S. Ruby, D. Thomas, and D. Heinemeier Hansson, Agile Web Development with Rails 4, 1st ed. Dallas, Texas - Raleigh, North Carolina: The Pragmatic Bookshelfl, 2013.

[12] F. Moyano, C. Fernandez, and J. Lopez, "Towards engineering trustaware future internet systems," in Advanced Information Systems Engineering Workshops, ser. Lecture Notes in Business Information Processing, X. Franch and P. Soffer, Eds. Springer Berlin Heidelberg, 2013, vol. 148 , pp. $490-501$.

[13] C. Dellarocas, "Designing reputation systems for the social web," SSRN Electronic Journal, 2010.

[14] S. Yelp, "3 an inquiry into effective reputation and rating systems," The Reputation Society: How Online Opinions are Reshaping the Offline World, p. 25. 